\title{
The Effect of In Ovo Exposition to Ethanol Upon Osteogenesis of the Chicken Embryo
}

\author{
Hadjira Boussouar $^{1}{ }^{*}$, Tarek Khenenou $^{2}$, Omar Bennoune $^{3}$ and Amine Berghiche ${ }^{4}$ \\ ${ }^{1}$ Department of Veterinary Sciences, Institute of Veterinary Sciences and Agronomic Sciences, Batna University 1, Batna 05000, Algeria \\ ${ }^{2}$ Laboratory of Animal Productions, Biotechnology and Health, Institute of Agronomic and Veterinary Sciences, Mohamed Cherif Messaadia \\ University, Souk Ahras, Algeria \\ ${ }^{3}$ ESPA Laboratory, Department of Veterinary Sciences, Institute of Veterinary Science and Agricultural Sciences, Batna University 1, Batna \\ 05000, Algeria \\ ${ }^{4}$ Laboratory of Science and Technique of Living, Institute of Agronomic and Veterinary Sciences, Mohamed Cherrif Messaadia University, \\ Souk Ahras, Algeria \\ "Corresponding author's Email: hadjiraboussouar05@ gmail.com; ORCID: 0000-0003-3404-7838
}

\begin{abstract}
Excessive alcohol consumption by a pregnant woman may delay foetal development and may cause malformations. In this study, the model of the chicken embryo to demonstrate the teratogenic effect of ethanol (33\%) on the chicken osteogenesis on the $10^{\text {th }}$ day of embryonic development have been used. 49 fertilized eggs were used in present investigation. Hence, different doses of ethanol were injected into the chicken embryos at $33 \%(20,40,80 \mu l)$ in the air space at gastrulation and, on the other hand, an equivalent amount of the mentioned doses of distilled water were injected into the control-group eggs which was done once in every two days in order to maintain a high concentration in the blood. Experiments were repeatedly and independently carried out for three times. The eggs were incubated in a humid incubator at the temperature of $37.7^{\circ} \mathrm{C}$ and at $60-65 \%$ of humidity. On the $10^{\text {th }}$ day of incubation, the embryos were taken out and fixed in formalin at $10 \%$. After that, the eggs were sectioned at $5 \mu \mathrm{m}$ of thickness with a Leica micrtome and, then, stained with the Hematoxylin and eosin. Histological examination has revealed that the exposition of chicken embryos to ethanol (33\%) delays the skeletal development in a dose-dependent manner by reducing the length of the cartilaginous proliferation zone and hypertrophic zone during the bone formation period. Furthermore, under the effect of ethanol, the cell proliferation activities were repressed. In conclusion, present results indicated that using ethanol to treat chicken embryos at early stages caused considerable malformations and a decreased in the embryo survival rate. The exposition to alcohol affects the chicken osteogenesis in a dose-dependent manner.
\end{abstract}

Key words: Chicken embryo, Ethanol, Malformations, Osteogenesis, Teratogenic effect

\section{INTRODUCTION}

Alcohol is considered as the most common teratogen in the occidental world. Its consumption during pregnancy may pave the way to a disease called Foetal Alcohol Syndrome or, under its softest form, Foetal Alcohol Effects (Chaudhuri, 2004). This is very worrying, if anyone consider the increase of alcohol consumption by women in the world (Chaudhuri, 2004). Despite the fact that the rate of alcohol consumption has been relatively steady through the last 30 years, the rate of women who consumed alcohol increased by $12.4 \%$ in 1991 and by $16.3 \%$ in 1995 . Meanwhile, the number of newborns suffering from the Foetal Alcohol Syndrome (FAS) quadrupled between 1979 and 1993 with an incidence rate of 6.7 per 10000 births in 1993 (Miller et al., 2001). The negative clinical results of alcohol consumption during pregnancy may include an increased neonatal mortality, head and facial anomalies, a microcephaly, body organs disorder (Bupp Becker and Shibley, 1998). Including growth delay, muscle and skeletal anomalies and intellectual and behavioural disability (McGill et al., 2009). Various animal models have been used by researchers in order to study the factors and effects of various alcohol-related diseases. Such models have helped researchers to explore the mechanisms by which shortterm and long-term consumption may interfere with the normal embryo-development processes (Kamran et al., 2011). 
The chicken embryo (Gallus gallus) is an extremely useful model for the development biology, experimental embryology and teratology (Drake et al., 2006). Accurate and full descriptions of the development of chicks are widely available (Drake et al., 2006). Using chicken models is very beneficial for the developmental researches. Fertile eggs are cheap, easy to find at stores and only an incubator is required for their development (Smith and Nagy, 2008). The shell can easily be fenestrated to view or manipulate the embryo directly. It can also be easily obliterated so that to continue the development process (Smith and Nagy, 2008). Maternal metabolism lacks an in ovo system that allows the direct isolation of teratogenic effects. All in a nutshell, the embryo model offers a cheap and practical system in which it is possible to apply modern experimental tools to know how a teratogen interferes with specific mechanisms underlying the organogenesis and the morphogenesis (Drake et al., 2006).

Hence, the aim of this work is to study the teratogenic effect of the in ovo exposition to ethanol on the osteogenesis in a system of a chicken-embryo model considering the injected ethanol dose and the embryonic development stage.

\section{MATERIALS AND METHODS}

\section{Ethical approval}

The experiment was carried out according to the National Regulations on Animal Welfare and Institutional Animal Ethical Committee.

\section{Experimental design}

Present investigation was carried out on a group of 49 embryonated of the broiler chickens (Hubbard F15) eggs, brought from the private hatchery "Coopérative agricole Errakhaà Wa Izddihar", located in Theniyetsaida (Ain Yagout - Batna) through the period from April 2017 to March 2018, Algeria. The eggs were divided into three groups: a non-treated negative control group $(\mathrm{n}=7)$, a positive control group, treated with distilled water, and which, in turn, was subdivided into three subgroups of six eggs each. These subgroups received respectively (20, 40 and $80 \mu \mathrm{l}$ ) of distilled water. A last group, exposed to ethanol 33\%, was also subdivided into three subgroups of eight eggs each. These subgroups received respectively (20, 40 and $80 \mu \mathrm{l}$ ) of ethanol 33\% (Table 1).

\section{Substance injection}

This particular step is crucial and necessitates a maximum sterility. Hence, a Bunsen burner was used for the substance injection in the air sacs (Cevik et al., 2007).

\section{Incubation}

The eggs were incubated during 240 hours (10 days) in a humid incubator at $37^{\circ} \mathrm{C}$ and $60-65 \%$ of humidity, and were automatically turned every four hours (Cevik and Lale Satiroglu, 2003; Aguilera et al., 2005).

\section{Visualisation of the skeleton}

The skeletal staining was done by the technique described by Sadeghi (2014): the embryos were eviscerated and the skeletons were cleared without being damaged. After that, they were fixed in ethanol absolute. The skeletal staining was done with Alizarin red at 0.001 $\%$. The samples were then rinsed by $\mathrm{KOH}$ at $1 \%, 3$ times during a week. The last step was the treatment of the samples with ascending concentration sets of glycerol in $\mathrm{KOH}$ at $1 \%$ during 24 hours in every step. Finally, the samples were placed in glycerol.

\section{Histological examination}

The samples were fixed with $10 \%$ buffered formalin, passed through to a series of ethanol from $80 \%$ to $100 \%$, then cleared with xylene during one hour in each shower and then incorporated in paraffin. $5 \mu \mathrm{m}$ bone sections were taken by a microtome (Leica), the slides were then H\&E stained and analysed under an optic microscope Carl Zeiss Axioskop 20 connected to a digital video camera DOM 300 (Laanani et al, 2015; Khenenou et al, 2017; Khenenou et al, 2019).

Table 1. Treatments, subgroups and number of eggs in each gruoup of study

\begin{tabular}{llcc}
\hline Group & Treatment & Subgroup & $\begin{array}{c}\text { Number } \\
\text { of eggs }\end{array}$ \\
\hline $\begin{array}{l}\text { A : Negative } \\
\text { control }\end{array}$ & No traited & & 7 \\
\hline B : Positive & Distilled & B1: $20 \mu \mathrm{l}$ & 6 \\
control & water & B2: $40 \mu 1$ & 6 \\
& & B3: $80 \mu 1$ & 6 \\
\hline C : Treated; & EtOH & C1: $20 \mu 1$ & 8 \\
ethanol & $(33 \%)$ & C2: $40 \mu 1$ & 8 \\
& & C3: $80 \mu 1$ & 8 \\
\hline
\end{tabular}

\section{Statistical analysis}

The statistical analysis of the experimental data was carried out using statistical software Graph Pad Prisme 5.01. The data concerning the length of the proliferation and hypertrophic zones were identified using a $\mathrm{T}$ test for 2 independent samples or an analysis of the one-way variance (One-way ANOVA); for both tests. $\mathrm{P}<0.05$ was considered as statistically significant between the control groups and those exposed to ethanol. 


\section{RESULTS AND DISCUSSION}

\section{Ethanol effects on the embryonic viability}

Present findings indicated that the in ovo injection of the distilled water at low quantities $(20 \mu \mathrm{l})$ had a negligible effect on the embryonic viability whose average embryo survival rate was $83.33 \%$; only a slight difference was noticed in comparison to the control group (85.72). In contrast, it was noticed a remarkable diminution of the embryonic $(58.33 \%)$ viability at higher water quantities (40 and $80 \mu 1$ ). When the groups exposed to ethanol 33\%, it was noticed a diminution of the embryo viability rate depending on the volume (the bigger the volume gets; the more the embryo mortality is), the average of the survival rate of embryos treated with $20 \mu \mathrm{l}$ was $56.28 \%$, but with an increase of the injected amount reaching $40 \mu 1$ and $80 \mu 1$, the average of the survival rate was reduced to $37.5 \%$ and $12.5 \%$ respectively (Table 2 ). The data illustrated in table 1 and figure 1 indicated that ethanol affects the embryonic survival rate at an early stage. Present results are in complete concordance with the study done by Zulifqar et al. (2015) which demonstrated that the treatment of the chicken embryos at early stages causes a decrease in the survival rate of chicken embryos.

Table 2. Average of survival rates in broiler chicken embryos treated with ethanol

\begin{tabular}{lccc}
\hline \multicolumn{1}{c}{ Quantity $(\boldsymbol{\mu l})$} & $\mathbf{2 0}$ & $\mathbf{4 0}$ & $\mathbf{8 0}$ \\
$\begin{array}{lccc}\text { Group } \\
\begin{array}{l}\text { Negative control ; } \\
\text { no traited }\end{array}\end{array}$ & $85.72 \%$ & $85.72 \%$ & $85.72 \%$ \\
\hline $\begin{array}{l}\text { Positive control; } \\
\text { distilled water }\end{array}$ & $83.33 \%$ & $58.33 \%$ & $58.33 \%$ \\
\hline Treated; ethanol & $56.28 \%$ & $37.50 \%$ & $12.50 \%$ \\
\hline
\end{tabular}

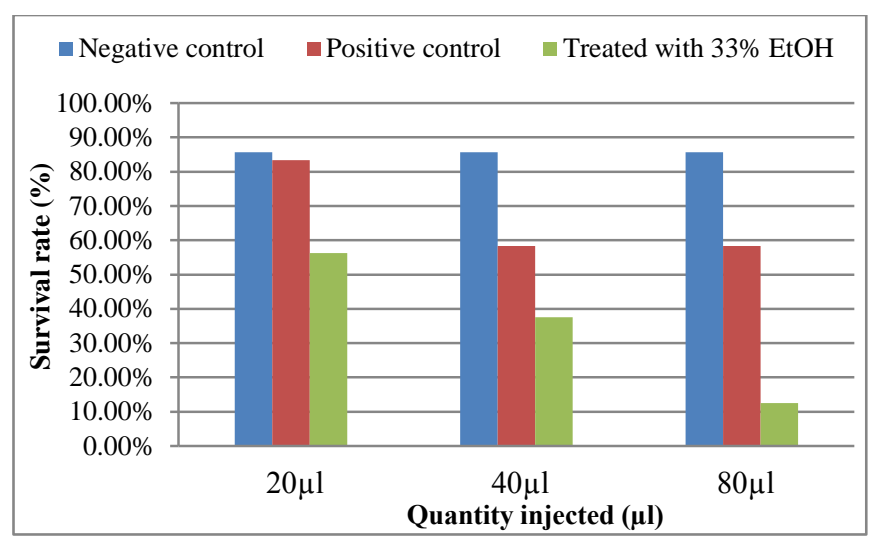

Figure 1. The effect of ethanol on broiler chicken (Hubbard F15) embryo survival rate, Algeria (April 2017 to March 2018).

\section{Special staining}

The stereomicroscopic observation of the embryos stained with Alizarin red has shown a dark red stain noticed on the long bones (Figure 2); Alizarin red staining has an affinity for calcium ions. This explains that there is an ossification process at the level of these bones. Hence, it was noticed that the ossification of long bones, such us the humerus bone, starts on the $10^{\text {th }}$ day of incubation for chicken embryos. This confirms the study done by Sawad et al. (2009).

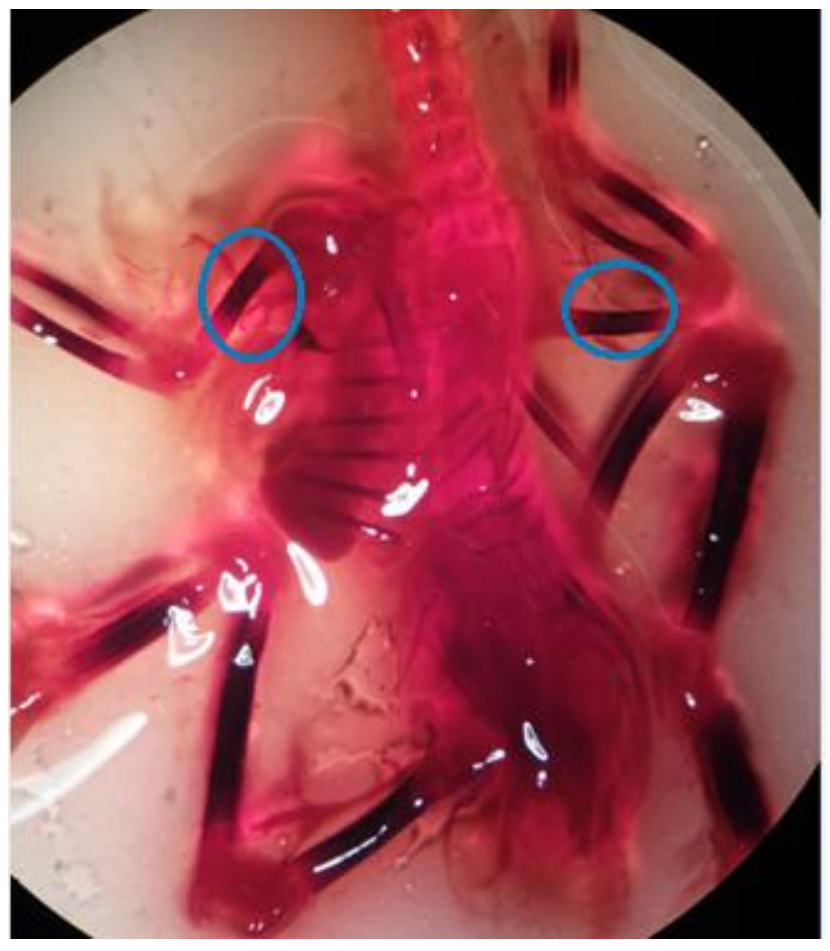

Figure 2. A broiler chicken (Hubbard F15) embryo after 10 days of staining with Alizarin red, Algeria (April 2017 to March 2018).

The effect of ethanol on the length of the proliferation and cartilaginous-hypertrophy zones

Long bones like the humerus bone develop by endochondral ossification, length measurements of the proliferation and cartilaginous-hypertrophy zones, particularly of the developing humerus bone, show the results below:

The length of the humerus-bone's proliferation zone of chicken embryos of the negative control group $(515.7 \pm 1.28 \mu \mathrm{m}, \mathrm{n}=4)$ was considerably $(\mathrm{P}<0.005)$ larger than that of the three groups exposed to ethanol $(20 \mu 1$, $40 \mu \mathrm{l}$ and $80 \mu \mathrm{l})$ whose lengths are $(505.9 \pm 1.14 \mu \mathrm{m}$, $498.1 \pm 1.93 \mu \mathrm{m}$ and $489.9 \pm 0.83 \mu \mathrm{m}$ ) respectively (Figure 3 ). Also, the cartilaginous-hypertrophy zoneof the humerus bone of the control group $(543.2 \pm 0.98 \mu \mathrm{m}, \mathrm{n}=4)$ was 
considerably $(\mathrm{P}<0.005)$ superior to that of the three groups exposed to ethanol $(20 \mu \mathrm{l}, 40 \mu \mathrm{l}$ and $80 \mu \mathrm{l})$ whose length is $(523.4 \pm 1.15 \mu \mathrm{m}, 515.5 \pm 0.88 \mu \mathrm{m}$, and $493.9 \pm 2.84 \mu \mathrm{m})$ respectively (Figure 4 ).
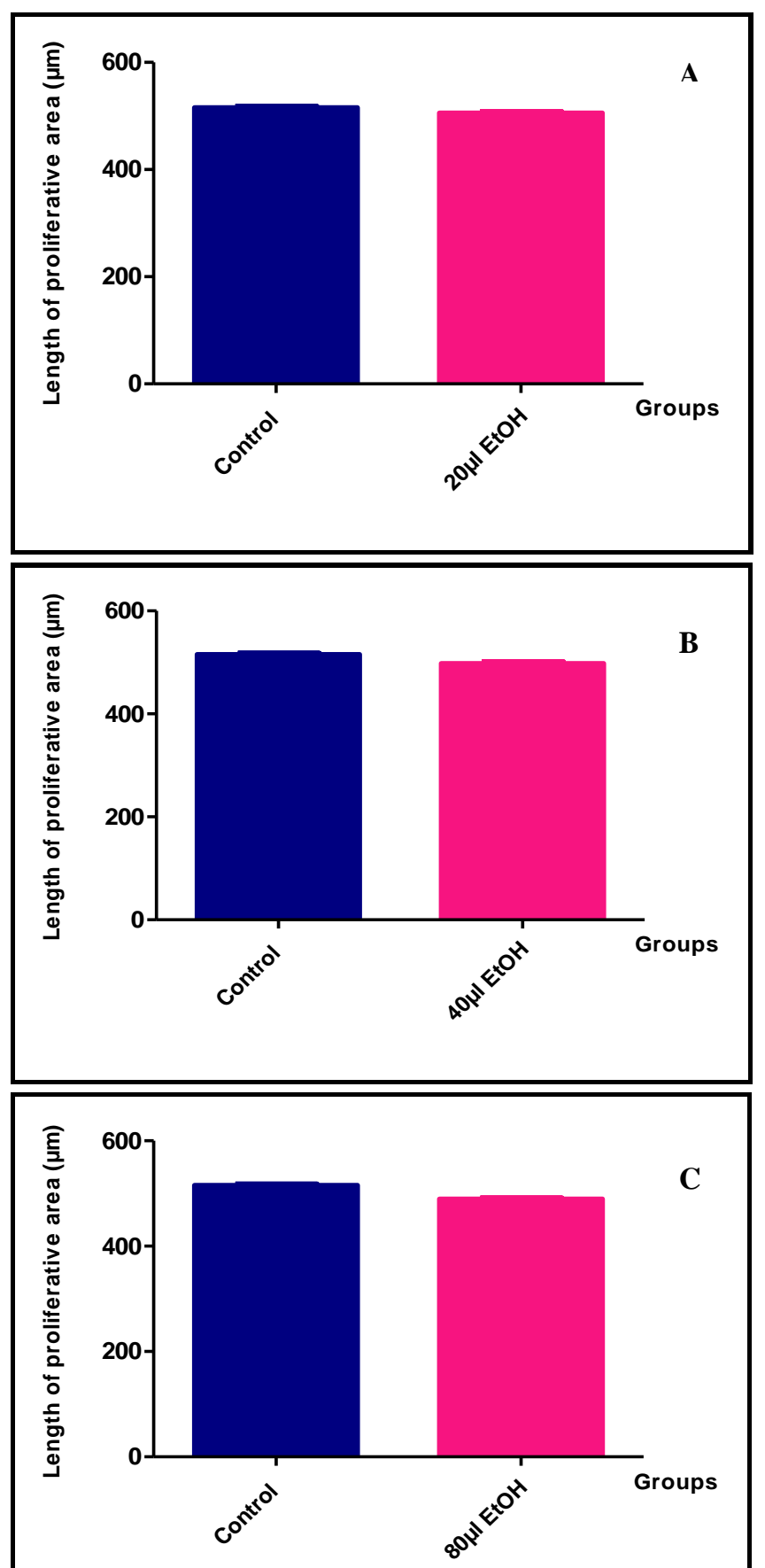

Figure 3. The ethanol effect on the length of the proliferative zone of the humerus of the broiler chicken (Hubbard F15) embryo, Algeria (April 2017 to March 2018) A. Exposition at $20 \mu \mathrm{l}$ of EtOH, B. Exposition at

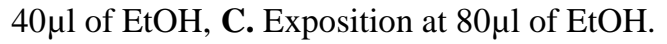
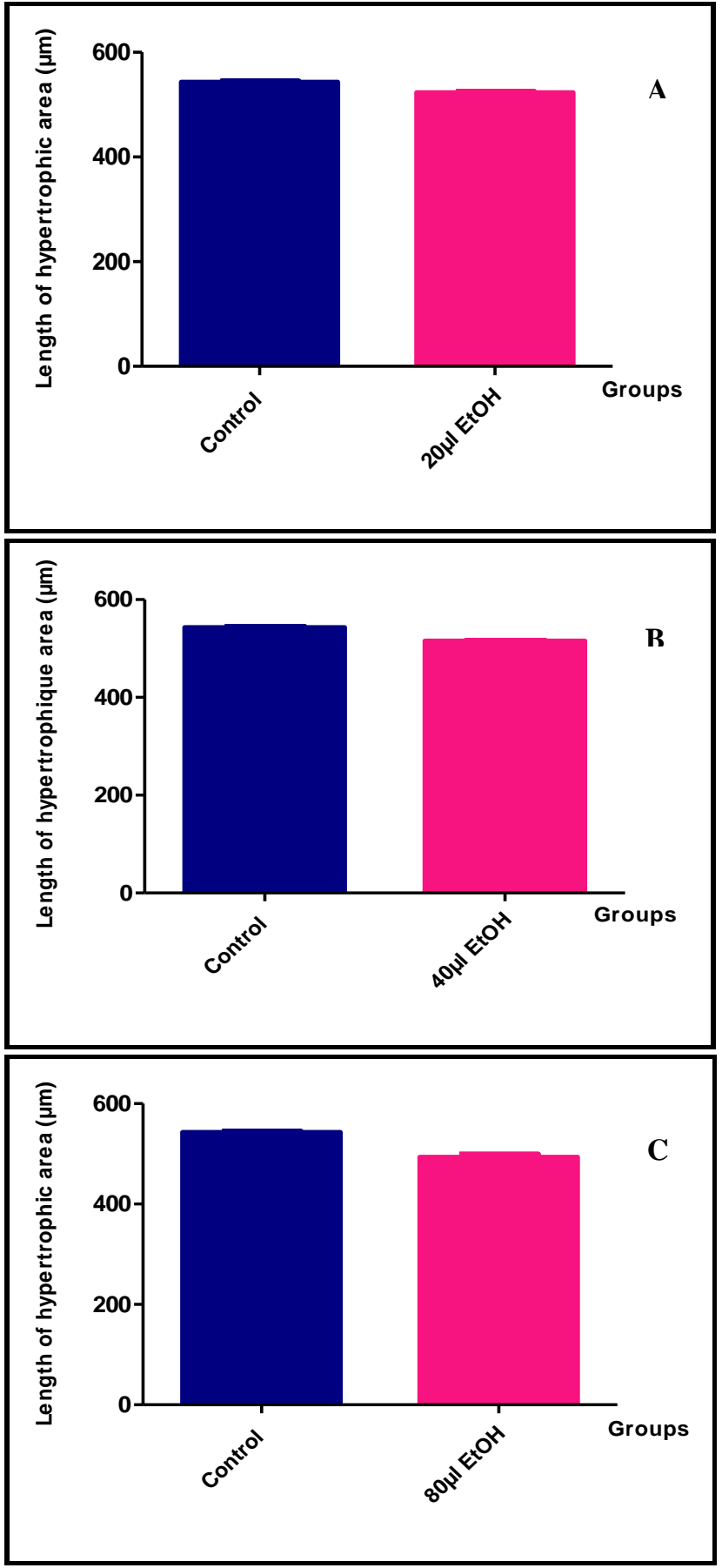

Figure 4. The ethanol effect on the length of the hypertrophic zone of the humerus of the broiler chicken (Hubbard F15) embryo, Algeria (April 2017 to March 2018); A. Exposition at $20 \mu \mathrm{l}$ of EtOH; B. Exposition at $40 \mu 1$ of EtOH; C. Exposition at $80 \mu 1$ of EtOH.

Present results demonstrated that exposure to ethanol, causing skeletal disturbances, affects on long bones by delaying ossification and total bone length which already reported by Clissmann and Brennan (2017). 
Present results revealed that ethanol inhibited the cell proliferation and the cartilaginous-hypertrophy process. This may have shortening effects on the proliferation and the cartilaginous-hypertrophy zones, because it was noticed that, at high ethanol concentrations, the length of the two zones of proliferation and cartilaginous hypertrophy of the humerus bone was considerably shortened.

Many studies were performed to determine the toxic effects of naturel and synthetic products on the embryos of chickens, including the studies undertaken by Afzal et al. (2019); Chaudhuri (2019) and Patel et al. (2019). Although the present research was planed base on chemical products that used in pharmaceutical production and considered as a less expensive and good antiseptic (Presterl et al., 2019).

The exposition to ethanol indicated the ossification process of chicken embryos in a dose-dependent manner. Therefore, it can be understood that the exposition to ethanol delays the skeletal development of chicken embryos at gastrula stage by repressing osteogenesis. Furthermore, ethanol effects on osteogenesis seem to be dose dependent, which has already been demonstrated by Zhong-yang et al. (2016).

\section{CONCLUSION}

Present findings indicated that ethanol is harmful and directly affects the embryonic viability. Also, it is noticed that exposition to ethanol at early stages causes a decrease in the survival rate of embryos in a dose-dependent manner. The embryos exposed to ethanol have indicated a delay in the skeletal development by a shortening of the length of the proliferation and cartilaginous-hypertrophy zones. This effect is considerable at higher doses. In conclusion, ethanol has negative effects on the embryonic development; these include a delay in the growth and skeletal anomalies.

\section{DECLARATIONS}

\section{Competing interests}

The authors have no competing interests to declare.

\section{Consent to publish}

All authors gave their informed consent prior to their inclusion in the study.

\section{Author`s contributions}

Boussouar, Khenenou and Bennoune were involved in the collection of data, statistical analysis and drafting of the manuscript. Khenenou and Bennoune read and approved the final manuscript.

\section{REFERENCES}

Aguilera Y, Dorado ME, Prada FA, Martınez JJ, Quesada A and Ruiz-Gutie'rrez V (2005). The protective role of squalene in alcohol damage in the chick embryo retina. Experimental eye research, 80: 535-543. DOI:10.1016/j.exer.2004.11.003

Afzal G, Ali S, Kiran S, Mustafa G, Ahmad H I, Hameed S and Majeed J (2019). Toxicological effect of ethanol on the development of chicken embryo in ova. Pure and Applied Biology, 8(1): 882-892. DOI:http://dx.doi.org/10.19045/bspab.2019.80030

Bupp Becker SR and Shibley Jr IA (1998). Teratogenicity of ethanol in different chicken strains. Alcohol and alcoholism, 33(5):457- 464 DOI :https://doi.org/10.1093/alcalc/33.5.457

Cevik TA and Lale Satiroglu-TN (2003).The Effect of Ethanol Exposure on Extraembryonic Vascular Development in the Chick Area Vasculosa. Cells Tissues Organs, 175:84-97. DOI: $10.1159 / 000073752$

Cevik TA, Gulcin A, Ilgaz A, Deniz E and Candan O (2007). The effect of in ovo ethanol exposure on retina and optic nerve in a chick embryo model system. Reproductive Toxicology, 23: 75-82. DOI:10.1016/j.reprotox.2006.09.006

Chaudhuri JD (2004). Effect of a single dose of ethanol on developing skeletal muscle of chick embryos. Alcohol, 34: 279-283. DOI: 10.1016/j.alcohol.2004.07.012

Chaudhuri JD (2019). Effect of a single dose of ethanol on developing peripheral nerve of chick embryos. European Journal of Anatomy, 10(2): 53-60.

Clissmann D and Brennan D (2017) .Skeletal examination in a chick embryo model of fetal alcohol syndrome indicates impaired osteogenesis .Reproductive Toxicology, 72:33-34. DOI:10.1016/j.reprotox.2017.06.145

Drake VJ, Koprowski SL, Lough JW and Smith SM (2006). Gastrulating chick embryo as a model for evaluating teratogenicity: a comparison of three approaches. Birth defects research (Part A), 76: 66-71. DOI: 10.1002/bdra.20202

Kamran K, Khan MY and Minhas L (2011). Teratogenic effects of ethanol vapour exposure on chick embryos. Journal of the Pakistan medical association, 61:328.

Khenenou T, Boughrara M, Melizi M and Lamraoui R (2017). Histomorphological study of the bursae of Fabricius of broiler chickens during gumboro disease in Algeria area. Global veterinaria, 18(2):132-136. DOI:10.5829/idosi.gv.2017.132.136

Khenenou T, Berghiche A, Rahmoun DE, Miloudi A and Athamna H (2019). Morpho-histological comparisons of liver between the broiler chickens and wild boar in Algeria. Advances in animal and veterinary sciences, 7(1): 24-29. DOI:http://dx.doi.org/10.17582/journal.aavs/2019/7.1.24.29

Laanani I, Alloui N, Bennoune O, Laabaci W, Ayachi A and Benterki M S (2015). Clinical and histopathological 
investigations on inclusion body hepatitis in chickens in the Ain Touta area (Algeria). Global journal of animal scientific research, 3(1):72-76.

McGill J, Meyerholz D K, Edsen-Moore M, Young B, Coleman R A, Schlueter A J, Waldschmidt T J, Cook R T and Legge K L (2009). Fetal exposure to ethanol has long-term effects on the severity of influenza virus infections. The journal of immunology, 182: 7803-7808. 10.4049/jimmunol.0803881

Miller Jr RR, Heckel CD, Koss WJ, Montague SL and Greenman AL (2001). Ethanol- and nicotine-induced membrane changes in embryonic and neonatal chick brains. Comparative Biochemistry and Physiology, Part C, 130: 163-178. PII: S 1532 - 0456 Ž 01.00227 - 7

Patel S, Jana S, Chetty R, Thakore S, Singh M and Devkar R (2019). Toxicity evaluation of magnetic iron oxide nanoparticles reveals neuronal loss in chicken embryo. Drug and chemical toxicology, 42(1): 1-8. DOI:https://doi.org/10.1080/01480545.2017.1413110

Presterl E, Diab-El Schahawi M, Lusignani LS, Paula H and Reilly JS (2019). Basic Principles and Introduction to Disinfectants and Antiseptics for Skin, Mucosa, and Wounds. In Basic Microbiology and Infection Control for Midwives, Springer, Cham pp. 51-57.

Sadeghi F (2014). Two separated protocols with the most important comments for skeletal staining in embryonic and adulthood period in laboratory animals. Research papers, 11(2).

Sawad AA, Balsam AH and Al-Silawi AN (2009). Morphological study of the skeleton development in chick embryo (Gallus domesticus). International journal of Poultry science, 8(7):710- 714. DOI: $10.3923 /$ ijps.2009.710.714

Smith S M and Nagy L E (2008). The avian embryo in fetal alcohol research Alcohol: Methods and protocols. Humana Press, 447: 75-84. DOI:10.1007/978-1-59745-242-7_6

Zhong-yang L, Zheng-lai M, Wen-hui L, Xin C, Jian-long C, XiaoYu S, Manli C, Kenneth K H L and Xuesong Y (2016). Ethanol exposure represses osteogenesis in the developing chick embryo. Reproductive Toxicology, 62: 53-61. DOI:https://doi.org/10.1016/j.reprotox.2016.04.020

Zulifqar AL, Ayaz AS, Baradi W, Zameer AP, Khalid HL, Ghulam M M, Gulshan A S and Tahira J U (2015). Effects of a single dose of ethanol on survival rate and angiogenesis of chick embryo. Animal and Veterinary Sciences, 3(1): 8-11. DOI: 10.11648/j.avs.20150301.12 